\title{
Anti-Leishmanial drug Pentostam induced histological changes to liver and kidney in male BALB/c wild mice Nouara Elazirg Elammari ${ }^{1 *}$ and Salem Ramadan Sariti ${ }^{2}$ \\ ${ }^{1}$ Department of Parasitology of Medicine faculty-Benghazi University. \\ ${ }^{2}$ Biology Department, Libyan Academy, Misurara-Libya. \\ *Corresponding E-mail: nouara.elammari@uob.edu.ly
}

\begin{abstract}
Leishmaniasis is still a complex disease of (sub) tropical regions of the world caused by Leishmania spp. Antimonial pentostam is an anti-leishmaniasis drug used medically and it is the primary drug employed against leishmaniasis in Libya. It has multiple acute and chronic adverse effects which can be minimized by using the lowest effective dose. This work aimed to investigate the histological changes in the liver and kidneys affected by different doses of pentostam. Adult male of BALB/c wild mice was divided into four groups, 6 mice of each, and i.p. injected with $10 \mathrm{mg} / \mathrm{kg}, 20 \mathrm{mg} / \mathrm{kg}$, and $40 \mathrm{mg} / \mathrm{kg}$ pentostam in addition to a control group. After 28 therapeutic days and finishing the histological procedure to examine the collected tissue specimens, the obtained results of the liver tissue ranged from demonstrating cytoplasmic vacuoles, to hydropic degeneration, focal and hepatocytic necrosis, and lastly irregular area of hepatocytes with condensed pyknotic nuclei (hepatocyte necrosis). As well, the histological examination of kidney tissue ranged between demonstrating mild cloudy swelling (reversible hydropic degeneration), showed stromal aggregates of inflammatory cells (nephritis), and lastly showed renal tubule casts and necrosis. In a final conclusion, there are clear histological changes in the liver and kidneys, which had been seen in this study, which are dose-dependent changes.
\end{abstract}

Keywords: leishmaniasis, anti leishmaniasis drug, pentostam, histological examination of liver tissue, histological examination of kidney tissue.

Received: 16 July, 2021

Accepted: 25 July, 2021

Published: 01 August, 2021

\section{Introduction}

Basal Leishmaniasis is still a complex disease of (sub) tropical regions of the world caused by Leishmania spp. which is spread by sand fly [10]. As a fact, chemotherapy is central to the control and management of leishmaniasis. Moreover, antimonials remain the primary drugs against different forms of leishmaniasis in several regions [10]. However, Antimonial sodium stibogluconate (Pentostam $\left.{ }^{\circledR}\right)$ is an anti leishmaniasis drug that is used medically in a dose of $20 \mathrm{mg} \mathrm{sbv} / \mathrm{kg}$ per day for 28 days daily [1], it is the primary drug employed against leishmaniasis in Libya. This toxic antimonial compound has a narrow therapeutic window [9, 14]. After finishing the treatment, the patient should be evaluated to determine the drug outcomes. This evaluation should include the drug toxicity, especially on the liver and kidneys. Moreover, like any drug, Pentostam has multiple acute and chronic adverse effects which can be minimized by using the lowest effective dose. Therefore, awareness of the danger of using a high dose should be taken seriously. Considering that, we think it is important to investigate the tissue damage in the liver and kidney 
which is related to Pentostam side effects.

\section{Aim}

This work had been done to investigate the histological changes in the liver and kidney affected by different doses of the anti-leishmanial drug Pentostam.

\section{Materials and Methods}

Drug for in-vivo administration: Sodium stibogluconate injection B.P. (pentostam $®$ ), equivalent to pentavalent antimonite each $\mathrm{ml}$ contains $100 \mathrm{mg}$ are available in $30 \mathrm{ml}$ bottle, which obtained from the Libyan Health Ministry. Pentostam was prepared into three concentrations $10 \mathrm{mg} / \mathrm{kg}, 20 \mathrm{mg} / \mathrm{kg}$, and $40 \mathrm{mg} / \mathrm{kg}$, and have been given intraperitonally (i.p), each mouse received the determined dosage once a day in $1 \mathrm{ml}$ normal saline for 28 consecutive days.

The experimental animals: Adult male of BALB/c wild mice has been used weighting $25-39 \mathrm{~g}$ at the age of 8-12 weeks. Animals were fed a standard laboratory diet and tap water during the experiment. After 2 weeks of adaptation, all animals were randomly divided into four groups of six mice of each: Group 1: Served as a control group and received $1 \mathrm{ml}$ i.p. of normal saline once daily. Group 2: Received $10 \mathrm{mg} / \mathrm{kg} / \mathrm{day}$, i.p. Group 3: Received $20 \mathrm{mg} / \mathrm{kg} /$ day, i.p. Group 4: Received $40 \mathrm{mg} / \mathrm{kg}$, i.p.

Histological procedure: The selected tissue where R.t lobe of the liver and longitudinal section from both kidneys. Moreover, the collected liver and kidney specimens of each individual were fixed in $10 \%$ formalin to prevent degradation. Then specimens were dehydrated and embedded in paraffin before microtome sectioning. However, the sections undergo tissue processing and are stained by PAS stain to be examined by histopathological test. After all, the stained slides were observed at $100 \mathrm{x}$ magnifications using a Nikon's brightfield compound Nikon microscope (Model YS100). The changes in lobular architecture, fatty changes, nuclear alterations, and congestion of the sinusoids were evaluated in liver specimens. Similarly, changes in the cytoarchitecture of the glomeruli, proximal and distal convoluted tubules, and interstitium were evaluated in kidney specimens. The assessment has been done in Al-Saleem medical laboratory-Benghazi-Libya.

\section{Results}

After 28 i.p. Pentostam therapeutic days and finishing the histological procedure of the collected tissue specimens, the obtained results were as follows:

\section{The liver tissue specimens:}

Experimental group 1: Histological examination of liver in the Control group displayed normal microstructure and showed the arrangement of hepatocytes in the form of anastomosing plates of one to two cell thicknesses. These plates are separated by blood sinusoids as is illustrated by the photomicrograph in figure 1 . 


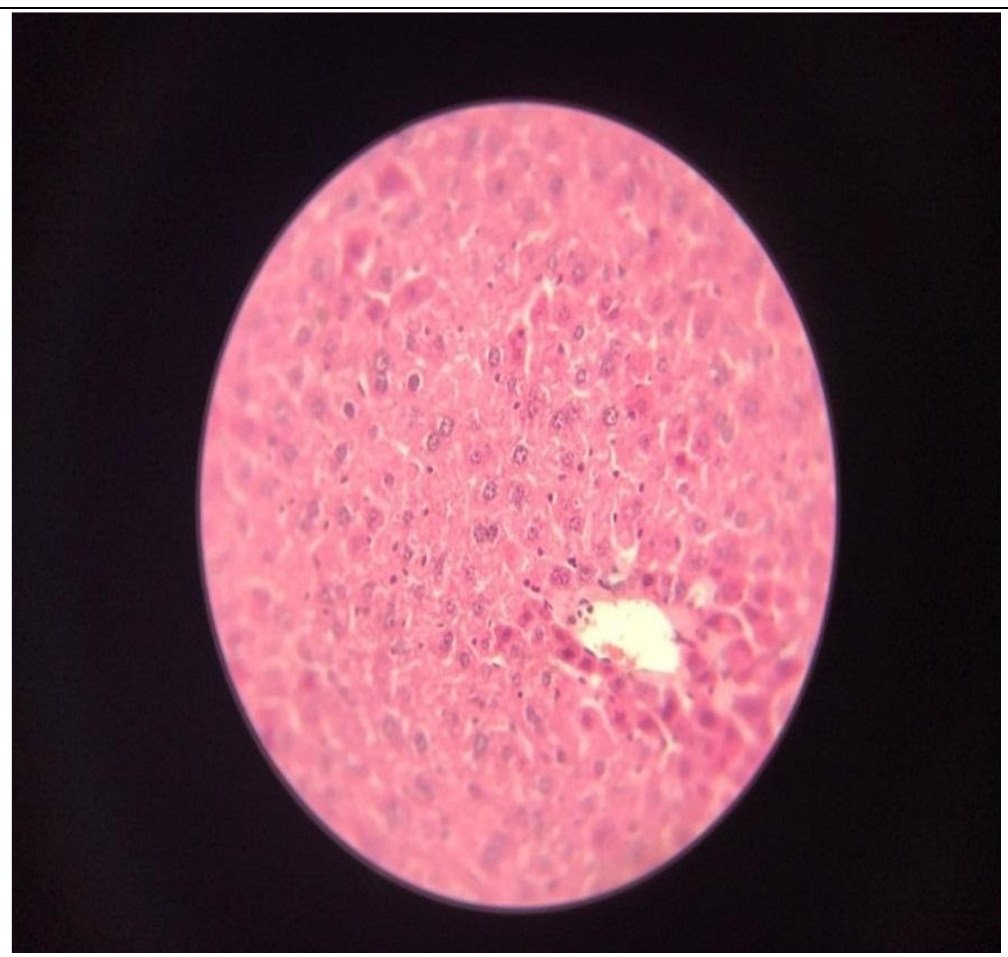

Figure 1: Liver tissue specimen of the control group shows normal hepatocytes and sinusoids.

Experimental group 2: Histological examination of liver in group 2, received $10 \mathrm{mg} / \mathrm{kg}$ which demonstrated cytoplasmic vacuoles (hydropic degeneration) as it is illustrated by the photomicrograph in figure 2 .

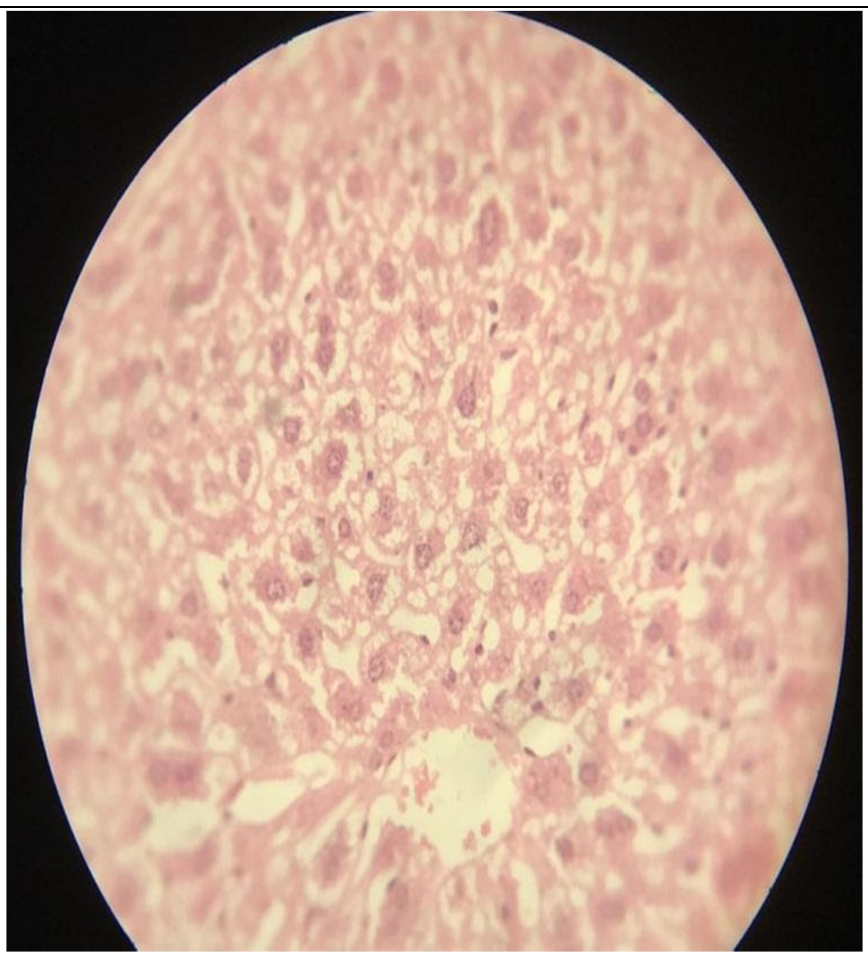

Figure 2: Liver tissue specimen of group 2. 
Experimental group 3: Histological examination of liver in group 3, received $20 \mathrm{mg} / \mathrm{kg}$ which shows hydropic degeneration, focal and hepatocytic necrosis as it is illustrated by the photomicrograph in figure 3 .

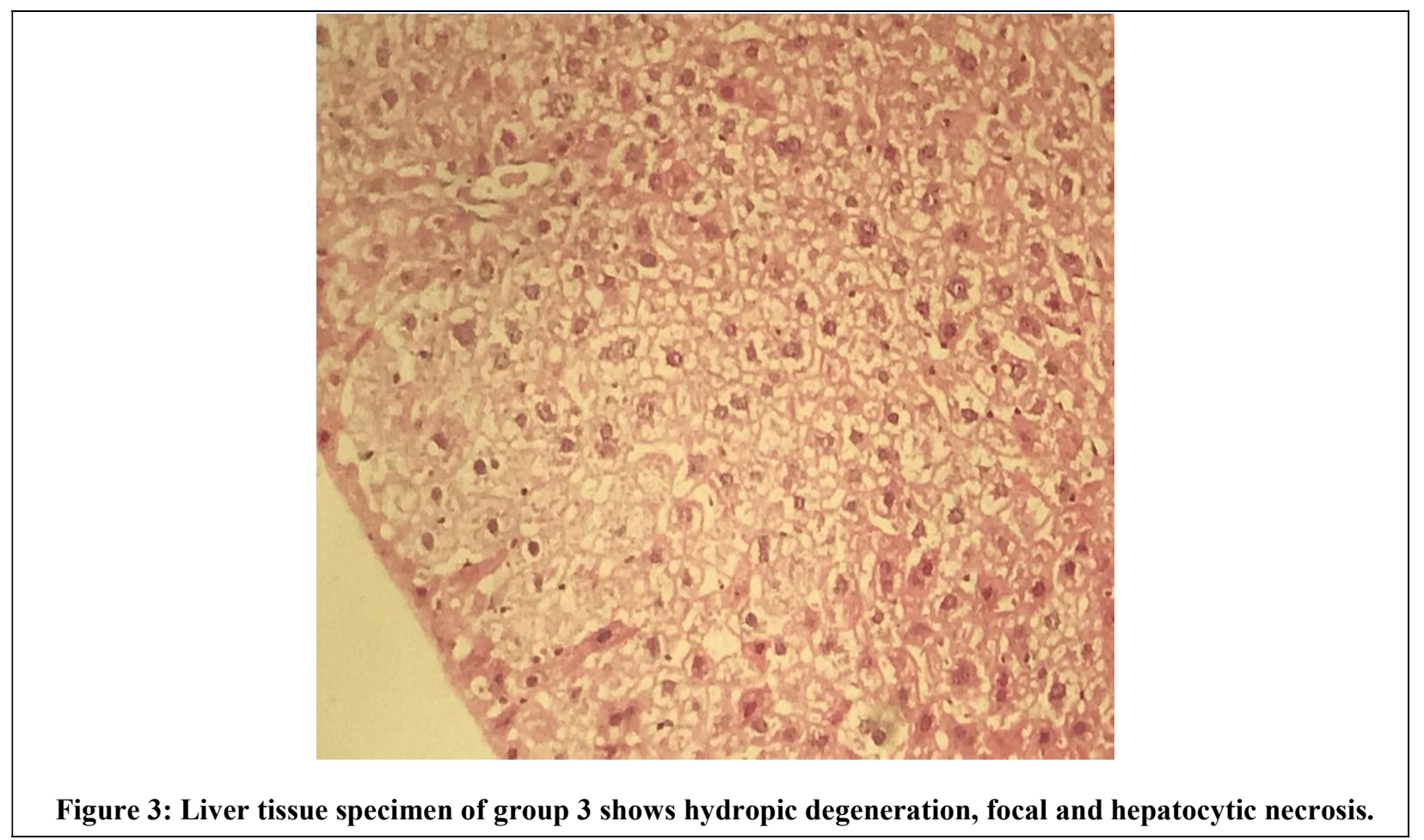

Experimental group 4: Histological examination of liver in group 4, received 40mg/kg shows an irregular area of hepatocytes with condensed pyknotic nuclei (hepatocyte necrosis) as is illustrated by the photomicrograph in figure 4

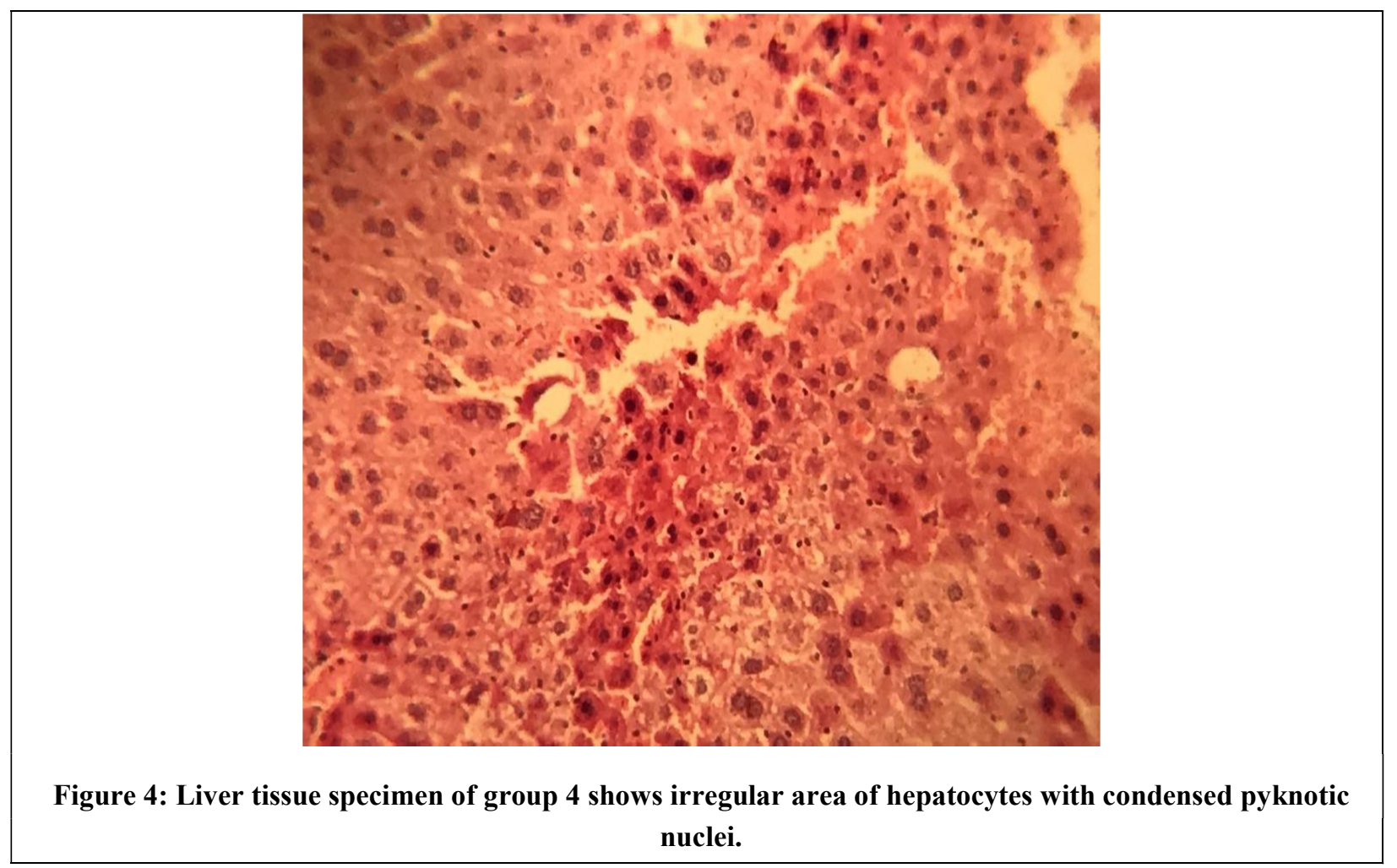


The kidney tissue specimens:

Experimental group 1: Histological examination of kidney in the Control group showing the morphology of renal unit composed of glomeruli and tubules as it is illustrated by the photomicrograph in figure 5 .

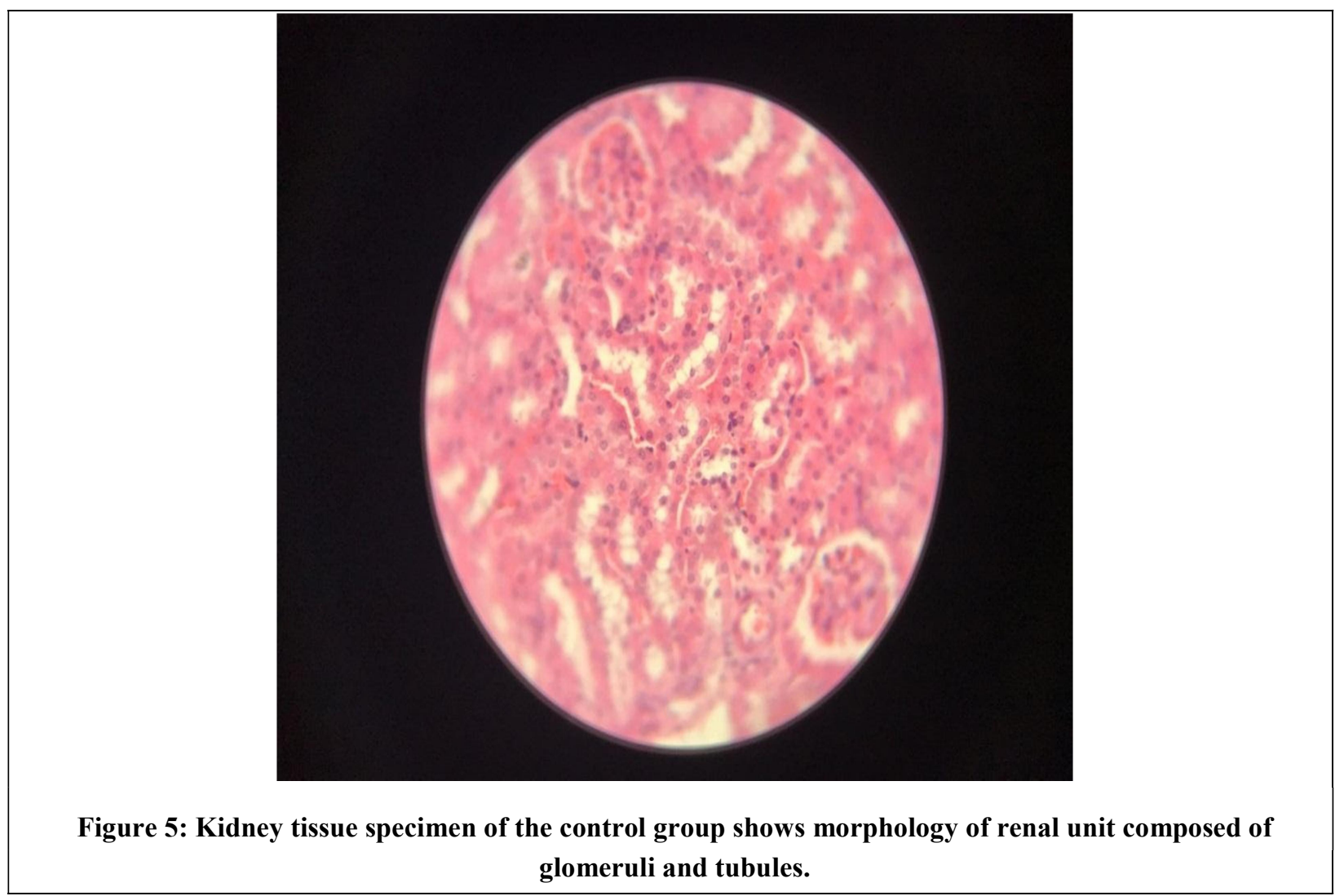

Experimental group 2: Histological examination of kidney in group 2, received $10 \mathrm{mg} / \mathrm{kg}$ which demonstrated mild cloudy swelling (reversible hydropic degeneration) as is illustrated by the photomicrograph in figure 6 .

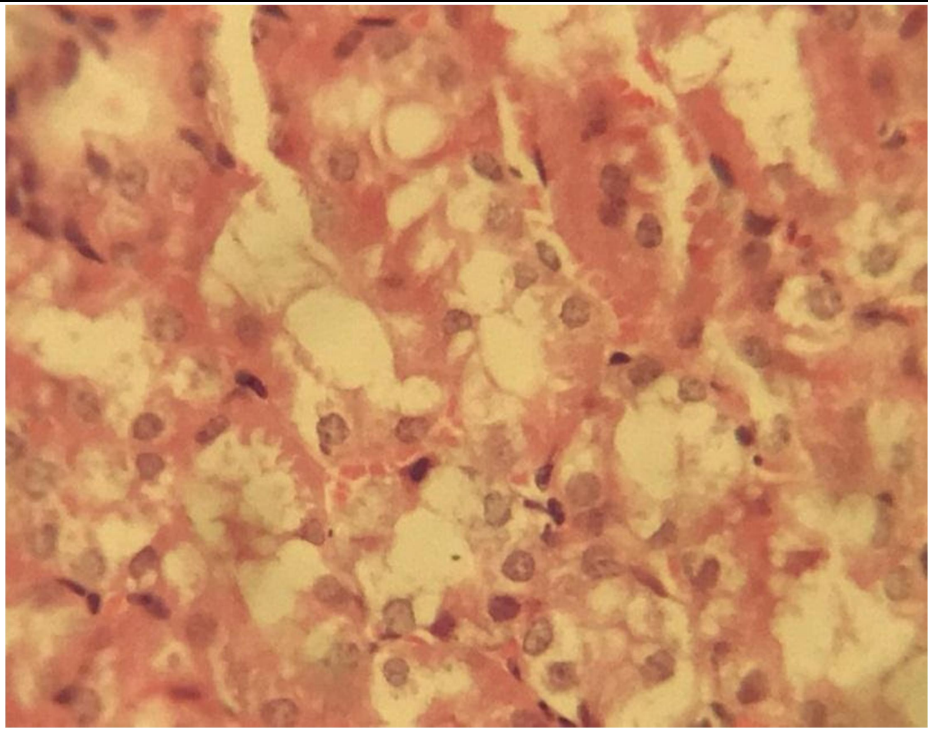

Figure 6: Kidney tissue specimen of group 2 shows mild cloudy swelling. 
Experimental group 3: Histological examination of kidney in group 3, received $20 \mathrm{mg} / \mathrm{kg}$ showed stromal aggregates of inflammatory cells (nephritis) as it is illustrated by the photomicrograph in figure 7 .

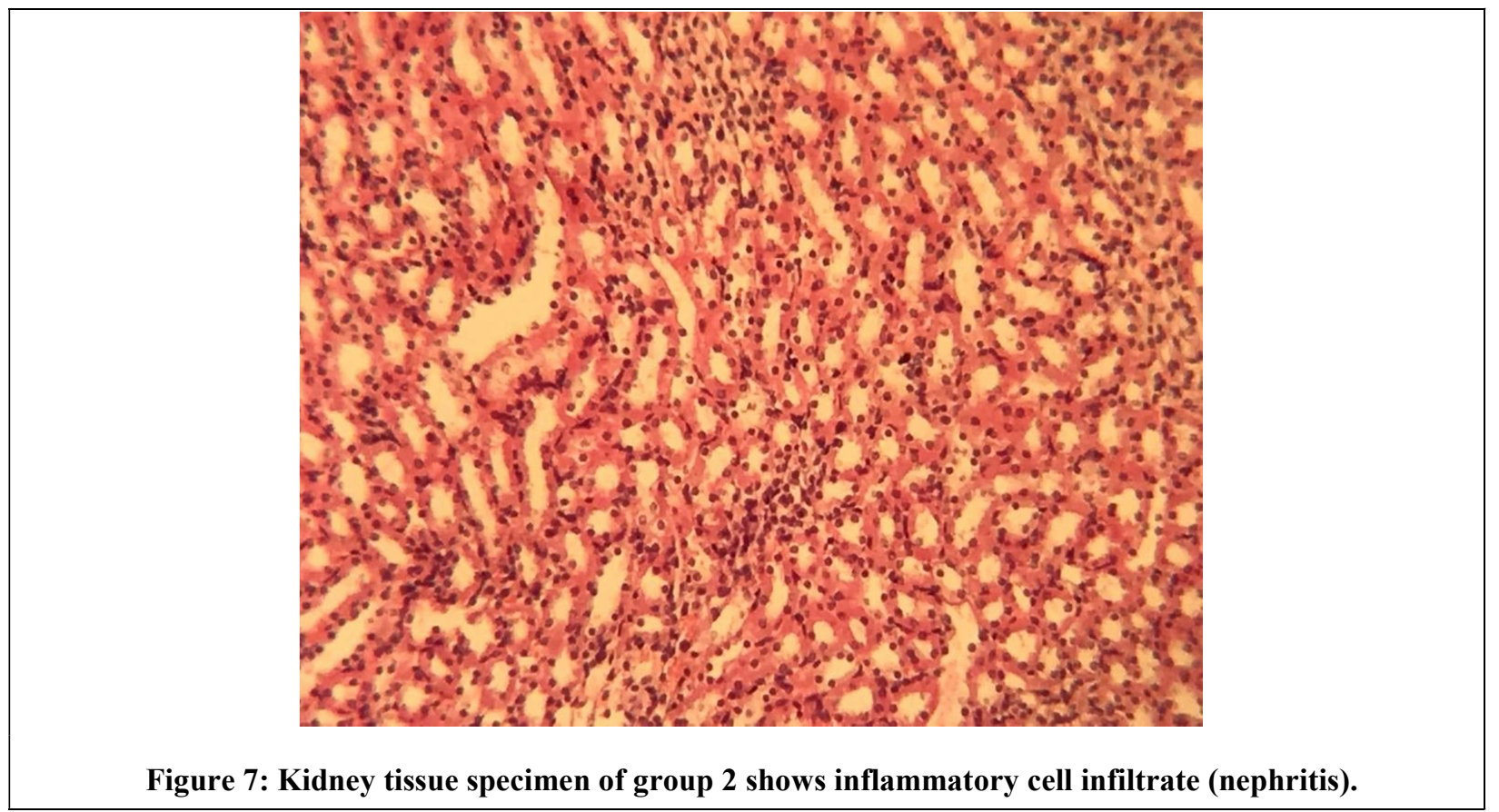

Experimental group 4: Histological examination of kidney in group 4, received $40 \mathrm{mg} / \mathrm{kg}$ showed renal tubule casts and necrosis as it is illustrated in figure 8 .

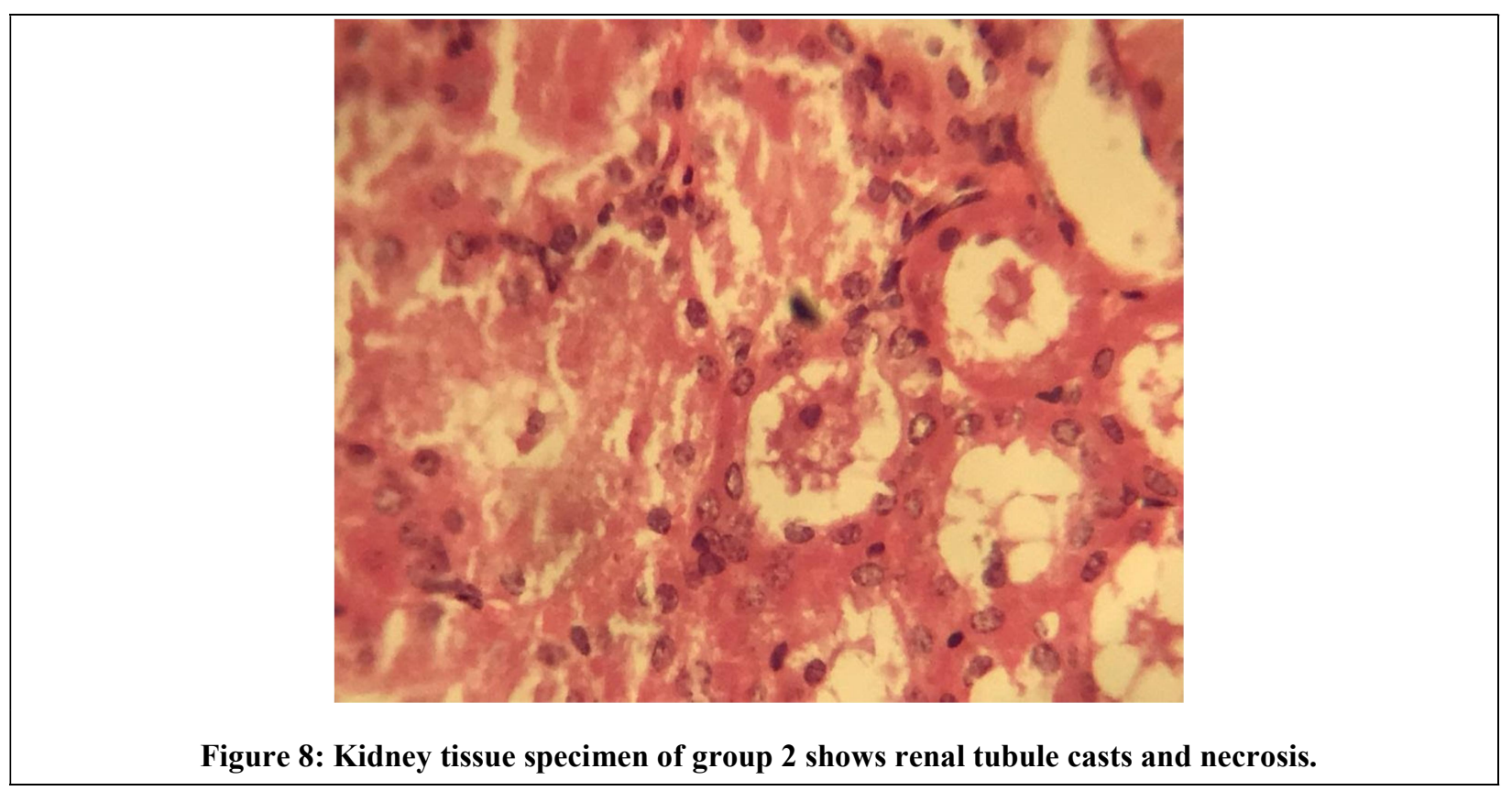

\section{Discussion}

As an interesting parasite, Leishmania has an intricate life cycle, and one of it is developmental forms, the amastigote, dwells inside the host immunological cells, which adds to the challenge of accessing this parasite with specific drugs. Nevertheless, the used chemotherapy should kill the intracellular parasites [6]. Therefore, 
antileishmanial chemotherapy remains the best means available to cure the disease and it should contain toxic chemicals to kill the intracellular Leishmania parasites. However, the liver is a well-known target organ of the toxic impact regarding its function in biotransformation and excretion of xenobiotics. After entering uptake, the liver is the first organ to be exposed by portal circulation [11]. Hepatotoxicity is toxicity to the liver, bile duct, and gall bladder. However, the liver is particularly susceptible to xenobiotics due to a large blood supply and its role in metabolism [2]. Consequently, the findings of the histological examination of liver tissue of the male BALB/c wild mice in this study were ranged between demonstrating cytoplasmic vacuoles (hydropic degeneration) in $10 \mathrm{mg} / \mathrm{kg}$ Pentostam group, to hydropic degeneration, focal and hepatocytic necrosis in $20 \mathrm{mg} / \mathrm{kg}$ Pentostam group, and lastly, irregular area of hepatocytes with condensed pyknotic nuclei (hepatocyte necrosis) in $40 \mathrm{mg} / \mathrm{kg}$ Pentostam group as it is illustrated in figures 2, 3, and 4 . These findings are in agreement with the fact that the liver is highly susceptible to be affected by toxic chemicals [2]. For a long time, [8] clarified that in less acute presentations, liver histological changes can be very varied, as changes progress, appearances may mimic chronic hepatitis with portal inflammation, interface hepatitis, and fibrosis. In addition to that, acute hepatitis usually causes a lobular pattern of inflammation. The inflammation can be mild with minor infiltrates and spotty necrosis of single hepatocytes, or in severe cases cause widespread necrosis with architectural disturbance (lobular disarray) or collapse [13]. However, it seems that the accumulation of Pentostan is directly toxic to hepatocytes, this hepatocyte toxicity is increased by increasing the Pentostan dose [3] concluded that the liver syndrome's intensity correlated with the increase in dose and duration time.

In the same line, the kidney is a vital organ of the body and proper kidney functioning is important to maintain homeostasis. The kidney is not only involved in the removal of wastes from blood but it is also responsible for selective reabsorption, which helps in maintaining the volume and $\mathrm{pH}$ of blood and body fluids, erythropoiesis, and help in regulating blood pressure by producing the enzyme rennin. The kidney is one of those organs, which are severely affected by different toxic chemicals $[5,7]$. Unfortunately, Kidneys are highly susceptible to toxicants for two reasons: i. a high volume of blood flows through it and ii. They filtrate large amounts of toxins that can be concentrate in their tubules. Anyway, Nephrotoxicity is toxic to the kidneys which may result in systemic toxicity causing decreased ability to excrete the body wastes, inability to maintain the body fluid and electrolyte balance, and decreased synthesis of essential hormones [2,4]. Nephrotoxicity induced by drugs is common in children and underlying renal disease and cardiovascular disease. Drugs can cause acute renal injury, intrarenal obstruction, nephrotic syndrome, interstitial nephritis. Certain drugs can cause alteration in intraglomerular hemodynamics, inflammatory changes in renal tubular cells leading to acute kidney injury [12]. Consequently, the findings of the histological examination of kidney tissue of the male $\mathrm{BALB} / \mathrm{c}$ wild mice in this study were ranged between demonstrating mild cloudy swelling (reversible hydropic degeneration) in $10 \mathrm{mg} / \mathrm{kg}$ Pentostam group, to showed stromal aggregates of inflammatory cells (nephritis) in $20 \mathrm{mg} / \mathrm{kg}$ Pentostam group, and lastly showed renal tubule casts and necrosis in $40 \mathrm{mg} / \mathrm{kg}$ Pentostam group. These findings are in agreement with that observation obtained by Furhan et al., as he described that the necrosis of hematopoietic tissue, vacuolation of tubule cells, dilation of glomerular capillaries, and degeneration of epithelial cell lining are some of the pathological changes observed in the kidney of various toxins [5]. Finally, histological analysis of liver and kidney tissue seems likely to remain an important investigation to determine the drug toxicity and effectively. As a final point, it is worth remembering that it is imperative to include information on drug toxicity, which is essential when designing therapeutic guidelines. After all, In this study, after 28 i.p. Pentostam therapeutic days, which were administrated in different doses (10, 20, and $40 \mathrm{mg} / \mathrm{kg}$ ), clear histopathological changes were observed in the mice's liver and kidney tissue compared to the control group. In addition, these histological changes were clearly related to the Pentostam dose. In the meaning that, the histological changes were increased by increasing the Pentostam dose (dose-dependent changes). However, this study revealed that exposer to Pentostam for about one month can cause histological changes in the male of $\mathrm{BALB} / \mathrm{c}$ wild mice liver and kidneys even within the normal therapeutic dose. 


\section{Conclusion:}

Histological analysis of liver and kidney tissue still an important role to evaluate drug toxicity. However, in this study, we found clear histological changes in the liver and kidneys which are related to the Pentostam dosage (dosedependent changes). Therefore, it will be important to investigate the biological function of the liver and kidneys affected by the anti-leishmanial drug Pentostam in the male same different doses which have been used in this study.

\section{DECLARATIONS}

\section{Funding}

This research did not receive any specific grant from funding agencies in the public, commercial, or not-for-profit sectors.

\section{Conflicts of Interest}

The authors declared no potential conflicts of interest with respect to the research, authorship, and/or publication of this article.

\section{REFERENCES}

[1] Abyot Desta, Solomon Shiferaw, Andargachew Kassa, Techalew Shimelis, and Simachew Dires. Leishmaniasis for the Ethiopian Health Center Team. EPHTI, 2005.

[2] Afshar S., AA Farshid, R Heidari and M Ilkhanipour. Histopathological changes in the liver and kidney tissues of Wistar albino rat exposed to fenitrothion. Toxicology and Industrial Health 2008; 24: 581-586.

[3] Al-Jahdali, MO, Bin Bisher, AS Abu zeid, IM (2007) Physiological and histological alterations in rats liver induced by sumithion ${ }^{\circledR}$ NP 25/2.5 EC, an insecticide used in Dengue Fever Vector control in Jeddah Saudi Arabia. Saudi J Biol Sci 14: 43-51.

[4] Finn, WF. Renal responses to environmental toxins. Environ Health Perspect (1977) 20: 15-26.

[5] Furhan Iqbal, Irfan Zia Qureshi and Muhammad Ali. Histopathological Changes in the kidney of common carp, Cyprinus carpio, following nitrate exposure. J. res. Sci., 2004, 15(4), 411-418.

[6] Garcı 'a-Herna 'ndez R, Manzano JI, Castanys S, Gamarro F. Leishmania donovani develops resistance to drug combinations. PLoS Negl Trop Dis. 2012; 6(12):e1974.

[7] Hole, J. W. "Essentials of human anatomy and physiology", (1992) $4^{\text {th }}$ ed. Wm. C. Brown Publishers, Dubuque, $745-$ 749.

[8] Ludwig J, Moyer TP, Rakela J. The liver biopsy diagnosis of Wilson's disease. Methods in pathology. Am J Clin Pathol 1994; 102:443-6.

[9] Mitropoulos P, Konidas P, Durkin-Konidas M. New World cutaneous leishmaniasis: updated review of current and future diagnosis and treatment. J Am Acad Dermatol. 2010; 63(2):309-22.

[10] Ponte-Sucre Alicia, Francisco Gamarro, Jean-Claude Dujardin, Michael P. Barrett, Rogelio Lo 'pez-Ve 'lez, Raquel Garc 'a-Herna 'ndez, Andrew W. Pountain, Roy Mwenechanya, Barbara Papadopoulou. Drug resistance and treatment failure in leishmaniasis: A 21st century challenge. PLOS Neglected Tropical Diseases. December 14, 2017.

[11] Roganovic-Zafirova, D, Jordanova, M. Liver lesions in bleak (Alhurnus alburnus alborella Filippi) collected from some contaminated sites on lake Ohrid. A histopathological evidence. Ekol Zast Zivot Sred (1998) 6: 11-18.

[12] Shahrbaf Fatemeh Ghane, Farahnak Assadi. Drug-induced renal disorders. J Renal Inj Prev. 2015; 4(3): 57-60.

[13] Torbenson M. Biopsy interpretation of the liver. Wolters Kluwer Health, 2014.

[14] WHO http://apps.who.int/iris/handle/10665/255104. Accessed on 10 May 2017. 